\begin{tabular}{|c|l|}
\hline Title & $\begin{array}{l}\text { Transformation and characterisation of dissolved organic matter during the thermophilic aerobic biodegradation of } \\
\text { faeces }\end{array}$ \\
\hline Author(s) & Narita, Hiroki; Zavala, Miguel A ngel Lopez; Iwai, Kaori; Ito, Ryusei; Funamizu, Naoy uki \\
\hline Citation & $\begin{array}{l}\text { Water Research, 391919), 4693.4704 } \\
\text { https://doi.org/10.1016j.watres.2005.09.022 }\end{array}$ \\
\hline Issue Date & 2005-11 \\
\hline Doc URL & http:/hdl.handle.net/2115/7407 \\
\hline Type & article (author version) \\
\hline File Information & WR39_19.pdf \\
\hline
\end{tabular}

Instructions for use 


\title{
Transformation and characterization of dissolved organic matter during the thermophilic aerobic biodegradation of faeces
}

\author{
Hiroki Narita, Miguel Angel Lopez Zavala, Kaori Iwai, Ryusei Ito, Naoyuki Funamizu* \\ Hokkaido University, Graduate School of Engineering, Department of Environmental Engineering, \\ Kita-13, Nishi-8, Kita-ku, Sapporo 060-8628 Japan
}

\begin{abstract}
We conducted a comparison of the characteristics of dissolved organic matter (DOM) taken from the bio-toilet and other sources. A characterization of DOM was carried out to assess the stability of the compost generated during the thermophilic and aerobic biodegradation of faeces. In addition, levels of soluble microbial products generated in the bio-toilet composting reactor were compared with those taken from the other sources. The results showed that, $i$ ), the main component of DOM from the bio-toilet are solutes with molecular weight (MW) > 3,0000 Da (40\%), whereas micromolecules $(\mathrm{MW}<1,000 \mathrm{Da})$ constituted more than $60 \%$ of the DOM from other solid samples, while liquid samples reached even more than 90\%; ii), the DOM stabilization level in the composting reactor of the bio-toilet system was greater than that shown by DOM from other sources; iii), stabilization of DOM in the bio-toilet system was characterized by an increasing amount of macromolecules ( $\mathrm{MW}>30,000 \mathrm{Da}$ ) after a decreasing trend observed in the early stages of the biodegradation process; and $i v$ ), net production of lipopolysaccharide (LPS) in wastewater treatment plants is greater than in the bio-toilet.
\end{abstract}

Keywords: aerobic biodegradation of faeces, bio-toilet, compost stabilization, dissolved organic matter, KDO, LPS

\section{Introduction}

A bio-toilet is a new kind of dry composting toilet which contains a composting reactor under the

\footnotetext{
* Corresponding author: Tel. and fax: (+81-11) 706-6270; e-mail address: funamizu@eng.hokudai.ac.jp
} 
toilet bowl, along with ventilation and mixing mechanisms (Fig. 1). Sawdust is used for the bioconversion of human excreta as a bulky matrix for compost in the reactor which is kept at $60^{\circ} \mathrm{C}$. The bio-toilet is becoming increasingly available commercially and is now being used in Japanese public parks, sightseeing areas and households (Lopez Zavala et al., 2004).

Since the compost produced by the bio-toilet may be applied as an organic fertilizer rich in N, P and $\mathrm{K}$, or as a soil conditioner in private gardens, urban green areas and on agricultural land, its stability is an important factor for product quality assessment (Mondini et al., 1996; Lasaridi and Stentiford, 1998): i.e. the effects of compost application on plants (Zucconi et al., 1985; Gallardo-Lara and Nogales, 1987), the potential for nuisance odour generation (Miller, 1993), and pathogen regrowth (Finstein et al., 1987). Additionally, the stability of the compost can be used for monitoring process performance and for the comparative evaluation of different composting systems (Stentiford, 1993).

Although in conventional composting systems, certain methods for measuring stability of compost have been proposed based on physical characteristics (pile temperature, aeration demand, odour, colour and optical density of water extracts), chemical characteristics (volatile solids, C/N ratio, COD, polysaccharides, humic substances, etc.), and biological characteristics (respiration measured either as $\mathrm{O}_{2}$ consumption, $\mathrm{CO}_{2}$ production or heat generation, enzyme activities, ATP content, seed germination, plant growth, etc.), these methods have not obtained universal acceptance (Jimenez and Garcia, 1989; Lasaridi and Stentiford, 1996).

The type of treatment and the transformation method applied to organic matter (OM) that is used during the biodegradation process influences the degree of stability and consequently the quality of the final product. Approximately $50 \%$ of the OM is converted into inorganic compounds, mostly 
owing to the degradation of easily-degradable compounds utilized by such microorganisms as $\mathrm{C}$ and $\mathrm{N}$ derived from proteins, cellulose and hemicellulose. The residual OM contains microbial products along with the non-degradable OM, which together form the humic substances (HS). While the transformation of OM during conventional composting processes has been widely studied, most of the reports have focused on the $\mathrm{NaOH}$-extracted HS (Chen et al., 1989; Aoyama, 1991; Jimenez and Garcia, 1992; Ciavatta et al., 1993; Chen and Inbar, 1993; Frimmel et al., 1994; Chefetz et al., 1996).

We need to recognise, however, that the characterization of $\mathrm{OM}$ during its transformation is not easy, because OM contains several disparate substances, such as low molecular weight compounds (free amino acids and sugars), chemically heterogeneous macromolecules (enzymes, amino-sugar complexes, polyphenols, and HS) and particulate OM (biodegradable and non-biodegradable). Even so, the characterization of the composition of dissolved organic matter (DOM), a kind of the active $\mathrm{OM}$, is a better indicator of the overall transformation of $\mathrm{OM}$ than that which focuses solely on the $\mathrm{NaOH}$-extracted HS (Chefetz et al., 1998).

Since the majority of DOM in the effluent from the biological treatment processes is reported to be soluble microbial products (Chudoba, 1985; Gaudy and Blachly, 1985; Rittmann et al., 1987; Namkung and Rittmann, 1988; Schiener et al., 1998), and as some compounds, such as Lipopolysaccharide (LPS), represent the soluble microbial products (Sharon, 1975), it become possible to evaluate the stability of DOM.

Since no studies of the transformation of OM during the composting process in the bio-toilet have yet been reported, our objectives in this study were, $i$ ), to characterize the DOM in the compost from the bio-toilet and compare it with the characteristics of DOM in activate sludge, effluent from 
wastewater treatment plants, and other sources; ii), to evaluate the fate of OM during the thermophilic aerobic biodegradation of faeces in lab scale composting reactors; and, iii), to estimate the levels of stability of the soluble microbial products in the compost from the bio-toilet and other sources.

\section{Materials and methods}

\subsection{Characterization of DOM}

Table 1 summarizes the eight samples used for the characterization of DOM derived from several sources and treatment processes. Because DOM in bio-toilet compost that is applied to or disposed onto farm land, gardens, urban green areas or other soil systems, may be lixiviated from the soil and may thereafter reach groundwater, natural water streams, rivers and other water bodies, we extracted the solid samples by following the procedure described in the notification No. 46 issued by the Japanese Ministry of the Environment (Soil Environment Standard Permissibility Test) (JME, 1991). First, $10 \mathrm{~g}$ of the solid sample and $100 \mathrm{ml}$ distilled water were placed in 2 litres-Erlenmeyer flasks and shaken during 6 hours in a balancing shaking equipment. The liquids were then centrifuged at 3,000 rpm for 20 minutes. Finally, the supernatants were filtrated twice to obtain filtrates for each sample; the first was through a paper filter $(1 \mu \mathrm{m}$-size cut-off $)$, the second through a membrane filter (0.45 $\mu \mathrm{m}$-size cut-off).

These filtrates were filtrated by four ultra-filters with different cut-offs of molecular weight (MW): 1000, 3000, 10000, $30000 \mathrm{Da}$. Then, the five filtrate fractions were obtained as MW $<1,000$, $1,000<\mathrm{MW}<3,000,3,000<\mathrm{MW}<10,000,10,000<\mathrm{MW}<30,000$ and $\mathrm{MW}>30,000 \mathrm{Da}$.

Total organic carbon (TOC) and UV absorbance at $260 \mathrm{~nm}$ (E260) were measured in samples from each filtrate fraction by using respectively a TOC analyser (Shimadzu TOC-5000A) and a 
spectrophotometer (HITACHI U-2000).

\subsection{Evaluation of OM transformation}

The aerobic biodegradation of faeces was conducted in a lab-scale composting reactor kept at $60^{\circ} \mathrm{C}$ and with a $60 \%$ moisture content as described by Lopez Zavala et al. (2004) Figure 2 shows a schematic representation of the experimental device. 100g (dry basis) of sawdust taken from a bio-toilet under operation were put inside the reactor, and then $20 \mathrm{~g}$ (dry basis) of fresh faeces were thoroughly mixed into the sawdust. The moisture content of the sawdust-faeces mixture was adjusted to $60 \%$ by adding distilled water. The air flow rate and inlet pressure were set respectively at 60 $\mathrm{ml} / \mathrm{min}$ and $25 \mathrm{kPa}$. Input and output oxygen partial pressures were measured every 30 minutes. The oxygen utilization rate $(O U R)$ was calculated from measured data by the following equation,

$$
\operatorname{OUR}\left(m g \cdot h^{-1}\right)=\left(\left[\mathrm{O}_{2}\right]_{I}-\left[\mathrm{O}_{2}\right]_{O}\right) \text { and }\left[\mathrm{O}_{2}\right]=f \frac{P_{i} Q_{a} M_{m}}{R T}
$$

where $\left[\mathrm{O}_{2}\right]_{\mathrm{I}},\left[\mathrm{O}_{2}\right]_{\mathrm{O}}$ : mass flow rates of input and output oxygen $\left(\mathrm{mg} \mathrm{h}^{-1}\right)$, respectively; $f$ : units factor; $P_{i}$ : oxygen partial pressure $(\mathrm{kPa}) ; Q_{a}$ : air flow rate $\left(\mathrm{ml} \min ^{-1}\right) ; M_{m}$ : molecular mass of oxygen (g/mol); $R$ : gas constant $\left(8.31451 \mathrm{~Pa} \mathrm{~m}^{3} \mathrm{~K}^{-1} \mathrm{~mol}^{-1}\right) ; T$ : air temperature $(\mathrm{K})$.

The sawdust-faeces mixture in the reactor was sampled at $0,7,25,48,96$, and 264 hours. The extracts from each sample were obtained by the method described in Section 2.1. TOC and E260 of the five fractions were measured; the TOC/E260 was then calculated.

\subsection{Estimation of soluble microbial products}

Since LPS is a component of the outer membrane of bacteria, the decay process of Gram-negative bacteria produces and releases LPS into the surrounding water. LPS consists roughly of three parts; a hydrophobic part of fatty acids, a hydrophilic chain of oligosaccharide, and a core part of 2-keto-3-deoxyoctonic acid (KDO) (Stainer et al., 1986). Thus, KDO can be used as an indicator of 
the LPS produced during the biomass decay in both the bio-toilet composting process and other sources (Narita et al.,2005) .

We analyzed KDO for the filtrates prepared in the previous section by a method of reverse phase HPLC of fluorescence labelling (Takahashi, 1996). Filtrates were concentrated ten times by a rotary evaporator. In order to isolate KDO sugar from LPS polymer, filtrates were hydrolysed by the addition of $0.025 \mathrm{~N} \mathrm{HCl}$ at $80^{\circ} \mathrm{C}$ during 60 min under constant stirring (Narita et. al., 2004). Then, fluorescence labelling with 1,2-diamino-4,5-methylenedioybenzene-2HCl (MDB) was conducted at $60^{\circ} \mathrm{C}$ during $150 \mathrm{~min}$. We also estimated the KDO concentration for the non-hydrolysed samples.

The DOM was fractionated into its hydrophobic and hydrophilic parts by the Sep-Pak C18 non-polarity cartridge columns (Waters Inc.). The effluent from the columns was collected as the hydrophilic fraction. Finally, the TOC of the hydrophobic fraction was calculated from the difference between the TOC of all DOM and the TOC of the hydrophilic fraction.

\subsection{Cluster analysis}

Cluster analysis is one of the multivariate techniques which are recommended as powerful techniques for classifying and relating data. Its purpose is to group the objects as suggested by the data, not as defined a priori, so that objects in a given cluster tend in some respects to be similar to each other, while objects in different clusters will tend to be dissimilar. There are two main types of cluster technique: divisive and hierarchical (Kaufman and Rousseuw, 1990; Ramos, 2001).

In this study, we used the hierarchical cluster technique with the Ward method as an aggregation criteria to analyse the similarities and dissimilarities of data evaluated at this stage: i.e., for eight samples (liquid samples and extracts form solid samples), five filtrate fractions (based on four MW cut-offs), TOC, E260, and TOC/E260. 


\section{Results and discussion}

\subsection{Characterization of DOM from bio-toilet compost}

Figure 3 shows the composition of DOM based on the molecular weight and TOC of the sources. While the main constituent in BTCE (bio-toilet compost) was DOM of MW > 30,000 Da, the comparable fraction of the FE (faeces extract) sample was much smaller than that of BTCE. Since this result suggests the formation of new macromolecules as a result of the biodegradation of faeces, we consider the increase of macromolecules to be an indicator of OM stabilization. The particular DOM fraction with MW > 30,000 Da was also found in the samples of SE (soil extract), SMBRS (submerged membrane bioreactor supernatant) and ASCE (activated sludge compost extract). It was interesting to note that samples of BTCE and SE had a similar percentage level of DOM of MW > 30,000 Da.

DOM of 10,000 - 30,000 Da in the MW range was found in samples from FE, BTCE, ASCE and RW (river water). The percentage of the constituent in the BTCE and FE samples was of the same level, but the TOC of the FE sample was higher than that of BTCE. This implies that this fraction was reduced during biodegradation of faeces in the bio-toilet system. This DOM fraction was absent in samples from SE, SASCE (soil with an activated sludge compost extract), WWTPE (effluent from a wastewater treatment plant) and SMBRS (supernatant of a submerged membrane bioreactor. This reactor was located at the different wastewater treatment plant where we took WWTPE sample).

DOM within the MW range of 3,000 - 10,000 Da was mainly found in the extracts from solid samples of BTCE, ASCE, FE, SE and SASCE; in ASCE, the percentage of this fraction was twice as great as in the others. In the liquid samples, however, this constituent was negligible. DOM within the MW range of 1,000 - 3,000 was only found in BTCE, ASCE, FE, and SMBRS. The percentage 
of this fraction in BTCE was similar to that found in FE.

Finally, DOM whose MW was less than 1,000 Da formed the main constituent in the samples from all sources, except for BTCE. As for the percentages of this constituent in samples from BTCE $(20 \%)$ and FE (60\%), it is clear that micro-molecules were consumed to form new macro-molecules during the decomposition of faeces in the bio-toilet. It was important to note that the proportion of this constituent from SASCE was nearly $90 \%$, which is similar to that from the liquid samples. The proportion from other solid samples, however, was less than $60 \%$.

Figure 4 shows the ratio of TOC to E260 (TOC/E260) of each sample for five DOM size cut-offs. TOC/E260 for BTCE and ASCE increased with increasing DOM size, whereas TOC/E260 for FE, SE, SASCE, WWTPE and SMBRS decreased. Some researchers have reported the correlations between DOM biodegradability and specific UV absorbance, i.e. that biodegradability increases exponentially with decreasing UV absorbance (Gilbert, 1988; Zoungrana et al., 1998; Pinney et al., 2000; Kalbitz et al., 2003). TOC/E260 can be used as an indicator for the stability of DOM, and, as Fig. 4 shows, DOM in BTCE sample, followed by the RW and ASCE, was very stable compared with that in the other samples. While the TOC/E260 ratio of the samples from FE, SE, SASCE and SMBRS at small DOM size was high, the sample from BTCE had a low TOC/E260 ratio even at the fraction with less than 1,000 Da.

\subsection{Hierarchical cluster analysis}

The results of the cluster analysis for the eight samples (liquid samples and extracts form solid samples), five filtrate fractions (based on four MW cut-offs) and TOC/E260 are collected in Table 2 and illustrated in Fig. 5. Two groups of clusters were distinguished with a squared distance of over 40. One group consisted of BTCE, ASCE and FE. In this group, ASCE and FE formed a merged 
cluster with high similarities. This merged cluster was dissimilar to BTCE at the squared distance of 15, because the percentages of DOM over 30,000 Da and the TOC/E260 for ASCE and FE differed from that of BTCE. In the second group, constituted by SE, SASCE, WWTPE, SMBRS and RW, the relationship between SASCE and WWTPE offered the most similarity between clusters in terms of composition and stability. These results from the cluster analysis show that the DOMs from BTCE and ASCE share more characteristics than the DOMs from the effluents taken from biological wastewater treatment processes (WWTPE and SMBRS).

\subsection{Evaluation of OM transformation}

Figure 6 illustrates the typical oxygen utilization rate (OUR) for the experimental batch test. There were two peaks in the OUR profile; a large peak at six hours and a broad one at four days ( $96 \mathrm{~h})$. The broad peak suggests that something happened after the intense transformation of OM. In order to investigate the transformation of DOM during the composting process, we measured the molecular weight distribution and TOC in extracts from the compost for the different times, as shown in Fig. 7. It can be seen from Fig. 7 that, 1$)$, total TOC ( $0.45 \mu \mathrm{m}$ filtrate) decreased monotonically; 2$)$, the TOC values of MW fractions within the over 30,000 group and the 10,000 - 30,000 group began to decrease, then increased and finally decreased. The increase of TOC occurred at approximately the same time as the broad peak of OUR; 3), the time course of the TOC of the MW fraction within the 3,000-10,000 range group showed a peak at 25 hours; 4), the TOC peak appeared at 7 hours for the TOC of MW fraction of less than 1,000.

Figure 8 shows the molecular weight distribution taken at different reaction times in the extracts obtained from compost samples and from the bio-toilet compost (BTC, a sufficiently longer biodegradation time). The fraction of under the 1,000 Da group increased before the 25 hour peak, 
then decreased to more than $50 \%$ at the time at which the maximum OUR occurred (large peak). On the other hand, fractions of the MW range in the over 30,000, in the 1,000-3,000 and in the 10,000 - 30,000 Da groups, decreased, then increased over the time course. Indeed, the fraction over 30,000 Da was $20 \%$ at the time when maximum OUR occurred, whereas it had increased up to about $40 \%$ by the end of the experiment. These data imply that two different reactions occurred during the composting process of faeces: a reaction between the elapsed time 0 hour and 25 hour and a second reaction after 25 hour. The first reaction was characterized by the increase in the MW fraction of less than 1,000 Da and the decrease in large molecules having MW of over 30,000 Da. This reaction reflected the bio-degradation of organic matter in faeces that corresponded to the first large peak in the OUR measurement. In the second reaction, DOM having MW of less that 1,000 Da transformed to the DOM fraction with MW of more that 30,000 Da and this reaction was detected by the broad peak in the OUR profile.

Figure 9 illustrates the time course of the TOC/E260 ratio. BTC had the lowest values of TOC/E260 for all DOM size-cuts, because of its longest reaction time. TOC/E260 decreased, then increased, finally decreased for almost all size cut-off. The increase of TOC/E260 occurred at the time of the broad peak of the OUR profile (96 hour). This means that the trends of TOC/E260 are consistent with the trends of OUR, TOC and MW distribution, i.e. that the increase of TOC/E260 during the time course was accompanied with the increase of OUR during this transformation. We concluded that the complete stabilization of OM by bio-toilet can take over 10 days under the operational conditions similar to those obtaining during these experiments.

\subsection{Soluble microbial products released under the biomass decay}

Figure 10 shows the ratio of KDO to TOC for the filtrates (KDO/TOC) and the hydrophilic DOM 
fraction (KDO/Hi-TOC) for hydrolysed and non-hydrolysed samples from the bio-toilet, the other sources, and the treatment processes. KDO/TOC for the hydrolysed samples was a little larger than the ratios of non-hydrolysed samples, because KDO was released from the LPS polymer during its hydrolysis operation. The ratio of KDO to TOC in the hydrophilic fraction (KDO/Hi-TOC) was higher than KDO/TOC in those filtrates which included both the hydrophilic and hydrophobic fractions. As Fig. 10 shows, WWTPE and RW had large values of KDO/TOC and KDO/Hi-TOC, whereas SASCE, SE, SMBRS, and BTCE had small values. Since KDO is a good indicator of LPS generation under biomass decay (Narita et. al., 2005), it may be said from the data in Fig. 10 that, i), net production of LPS in wastewater treatment plants is greater than in the bio-toilet; $i$ ), little KDO generation in the bio-toilet can be a sign of complete DOM stabilization. This is because only a small amount of LPS remains, while TOC decreases with time means enough biodegradation of it; and the reason for this is that LPS is one of the compounds which represent the soluble microbial products (Sharon, 1975) and the products are biodegradable (Barker and Stuckey, 1999).

The evolution of KDO/TOC and KDO/Hi-TOC for both hydrolysed and non-hydrolysed samples taken at each time course is plotted in Fig. 11. The ratios for the hydrolysed samples decreased until the time of the maximum OUR (7 hours), then increased a little up until 24 hour, thereafter rapidly decreased, finally decreasing slowly. KDO/TOC and KDO/Hi-TOC for the non-hydrolysed samples (Fig. 11 (b)) showed a similar pattern to the hydrolysed samples for 96 hour. Thereafter, they gradually increased up to the end of the test. Since LPS is a product of the biomass decay process, we anticipated a tendency for both ratios to increase during the experiment. However, the evolution of the ratios for both hydrolysed and non-hydrolysed samples was inverted, especially in the early stage of the faeces degradation process. Faeces are rich in anaerobic mesophilic microorganisms, as 
is well known, but under the thermophilic and aerobic conditions, these microorganisms died, resulting in the release of LPS. Thereafter, owing to the biodegradability of LPS thermophilic microorganisms consumed LPS as a substrate, together with the OM contained in the faeces. This explains the tendency of the ratios to decrease. When the decay of the new biomass started (after 96 $\mathrm{h}$ of the time course), a release of LPS occurred to cause a small increase of KDO in the non-hydrolysed samples.

\section{Conclusions}

We investigated the characterization of DOM under the thermophilic aerobic biodegradation of faeces in order to assess the stability of the compost generated by the bio-toilet and compost taken from other sources. The conclusions resulting from this study are that:

a) The main component of DOM from the bio-toilet are solutes over 30,000 Da of molecular weight (40\%); on the other hand, micro-molecules $(\mathrm{MW}<1,000 \mathrm{Da})$ constituted more than $60 \%$ of the DOM from other samples, more even than $90 \%$ in the liquid samples.

b) The DOM stabilization level reached in the composting reactor of the bio-toilet system was greater than that shown by DOM from the other sources.

c) Stabilization of DOM in the bio-toilet system was characterized during the time course by, $i$,), an increase and then a decrease of DOM with $\mathrm{MW}<1,000 \mathrm{Da} ; i i)$, a decrease and then an increase mainly of DOM with MW > 30,000; and iii), a decrease, then an increase, and finally a decrease of the TOC/E260 for almost all size cut-off. To complete the stability of OM in the bio-toilet will take over 10 days.

d) Net production of LPS in wastewater treatment plants is greater than in the bio-toilet. Regarding the biodegradability of soluble microbial products, small KDO generation in the bio-toilet can be 
a sign of more complete DOM stabilization.

\section{Acknowledgements}

This work was supported by CREST from Japan Science and Technology Agency. We thank Mr. Toshihiro Kitsui (Seiwa Denko Co., Ltd.) for providing sawdust samples from the bio-toilet in his company.

\section{References}

Aoyama, M. 1991. Properties of Fine and Water-Soluble Fractions of Several Composts II. Organic Forms of Nitrogen, Neutral Sugars, and Muramic Acid in Fractions. Soil Sci. Plant Nutr. Vol.37, pp.629-637

Barker, D. J., Stuckey, D. C., 1999. A review of soluble microbial products (SMP) in wastewater treatment systems. Wat. Res. Vol. 33, No. 14, pp 3063-3082.

Chefetz, B., Hatcher, P.G. Hadar, Y. and Chen, Y. 1996. Chemical and biological characterization of organic matter during composting of municipal solid waste. J. Environ. Qual. Vol.25 pp.776-785.

Chefetz, B., Hatcher, P. G., Hadar, Y., Chen, Y., 1998. Characterization of dissolved organic matter extracted from composted municipal solid waste. Soil Sci. Soc. Am. J. Vol. 62, pp 326-332.

Chen, Y., Inbar, Y., Hadar, Y. And Malcolm, R.L. 1989. Chemical properties and solid-state CPMAS

${ }^{13}$ C-NMR of composted organic matter. Sci. Total Environ. Vol.81/82 pp.201-208.

Chen, Y. and Inbar, Y. 1993. Chemical and spectroscopic analyses of organic matter transformations during composting in relation to compost mturity. Pp. 551-600. In Hoitink, H.A.J. (ed.) Science and Engineering of Composting: Design, environmental, microbiological and utilization aspect. Renaissance Publications, Worthington U.S.A.. 
Chudoba, J. 1985. Quantitative estimation in COD units of refractory organic compounds produced by activated sludge microorganisms. Wat. Res. Vol.19 pp.37-43.

Ciavatta, C., Govi, M., Pasotti, L. and Sequi, P. , 1993. Changes in organic matter during stabilization of compost from municipal solid waste. Bioresource Technology Vol.43, pp141-145.

Finstein, M.S., Miller, F.C., Hogan, J.A. and Strom, P.F. 1987. Analysis of EPA guidance on composting sludge. Part III. Oxygen, moisture, pathgens. Biocycle Vol.28 pp.38-44.

Frimmel, F.H., Abbt-Braun, G., Hambsch, B., Huber, S., Scheck, C. and Scmiedel, U. 1994. Behavior and functions of freshwater humic substances - Some biological, physical and chemical aspecs. Pp.735-754. In Senesi, N. and Miano, T.M. (ed.) Humic substances in the global environment and implications on human health. Elsevier, Amsterdam.

Gallardo-Lara, F. and Nogales, R. 1987. Effect of the application of town refuse compost on the soil-plant system: A review. Biol. Waste. Vol.19 pp.35-62.

Gaudy, A.F. and Blachly, T.R. 1985. A study of the biodegradability of residual COD. J. WPCF Vol.57 pp.332-338.

Gilbert, E. 1988. Biodegradability of ozonation products as a function of COD and DOC elimination by the example of humic acids. Wat. Res. Vol.22 pp. 123-126.

Igresias Jimenez, E. and Perez Garcia, V. 1989. Evaluation of city refuse compost maturity: A review. Biol. Wastes. Vol.27 pp.115-142

Igresias Jimenez, E. and Perez Garcia, V. 1992. Determination of maturity indices for city refuse composts. Agriculture, Ecosystem and Environment Vol.38 pp.331-343 
Kalbitz, K., Schwesig, D., Schmerwitz, J., Kaiser, K., Haumaier, L., Glaser, B. and Ellerbrock, R.

2003. Changes in properties of soil-derived dissolved organic matter induced by

biodegradation. Soil Biology \& Biodchemistry. Vol.35 pp.1129-1142.

Kaufman, L., Rousseuw, P. J., 1990. Finding groups in data: an introduction to cluster analysis.

Wiley; New York, 344 pp.

Lasaradi, K. E. and Stentiford, E. I. 1996. Respirometric techniques in the context of compost stability assessment: principles and practice. pp.274-285. In Bertoldi, M., Sequi, P., Lemmens, B. and Papi, T. (ed.) The Science of composting, Part 1. Chapman and Hall, Glasgow.

Lasaradi, K. E., Stentiford, E. I., 1998. A simple respirometric technique for assessing compost stability. Wat. Res. Vol. 32, No. 12, pp 3717-3723.

Lopez Zavala, M. A., Funamizu, N., Takakuwa, T., 2004. Biological activity in the composting reactor of the bio-toilet system. Bioresource Technology Vol 96/7, pp.805-812.

Marschner, B., Kalbitz K., 2003. Controls of bioavailability and biodegradability of dissolved organic matter in soils. Geoderma. Vol. 113 pp 211-235.

JME, 1991. Soil Environment standard permissibility test. Notification No. 46 of the Japanese Ministry of the Environment.

Miller, F.C. 1993. Minimizing odor generation. pp. 219-241. In Hoitink, H.A.J. and Keener, H.M. (ed.) Science and Engineering of Composting. Ohio University, $\mathrm{OH}$.

Mondini, C., Chiumenti, R., da Borso, F., Leita, L., De Nobili, M., 1996. Changes during processing in the organic matter of composted and air-dried poultry manure. Bioresource Technology; Vol. 55 , pp 243-249.

Namkung, E. and Rittmann, B.E. 1988. Soluble microbial products (SMP) formation kinetics by 
biofilms. Wat. Res. Vol.20 pp.795-806.

Narita, H., Ishiki, I., Funamizu, N., Takakuwa, T., Nakagawa, H., Nishimura, S., 2004. Organic matter released from activated sludge bacteria cells during their decay process. Environmental Technology. ( in press ).

Pinney, M.L., Westerhoff, P.K. and Baker, L. 2000. Transformations in dissolved organic carbon through constructed wetlands. Wat. Res. Vol. 34 pp.1897-1911.

Ramos, M. C., 2001. Divisive and hierarchical clustering techniques to analyse variability of rainfall distribution patterns in a Mediterranean region. Atmospheric Research; Vol. 57, pp 123-138.

Rittmann, B.E., Bae, W., Namkung, E. And Lu, C.J., 1987. A critical evaluation of microbial product formation in biological processes. Wat. Sci. Technol. Vol.19 pp.517-528.

Schiener, P., Nachaiyasit, S. and Stuckey, D.C. 1998. Production of soluble microbial products (SMP) in an anaerobic baffled reactor: composition, biodegradability and the effect of process parameters. Environ. Technol. Vol.19 pp.391-400.

Sharon, N., 1975. Complex Carbohydrates; Their Chemistry, Biosynthesis and Functions. Addison Wesley Publishing Co., Boston

Shin, H. S., Kang, S. T., 2003. Characteristics and fates of soluble microbial products in ceramic membrane bioreactor at various sludge retention times. Wat. Res. Vol. 37, pp 121-127.

Stanier, R. Y., Ingraham, J. L., Wheelis, M. L., and Painter, P. R., 1986. The microbial world. $5^{\text {th }}$ ed. Prentice Hall. (in Japanese).

Steniford, E.I. 1993. Diversity of composting systems. pp.95-110. In Hoitink, H.A.J. and Keener, H.M. (ed.) Science and Engineering of Composting. Ohio University, OH.

Takahashi, R., 1996. Biochemical experimental methods No. 23. Protein and sugar chain research 
methods. $3^{\text {rd }}$ ed. Japan Science Society Press.

Zoungrana, C. J., Desjardins, R. and Prevost, M. 1998. Influence of remineralization on the evolution of the biodegradability of natural organic matter during ozonation. Wat. Red. Vol.32 pp.1743-1752.

Zucconi, F., Monaco, A., Forte, M. And de Bertoldi, M. 1985. Phytotoxins during the stabilization of organic matter. pp. 73-86. In Grasser, J.K.R. (ed.) Composting of Agricultural and Other Wastes. Elsevier Science, Amsterdam. 


\section{List of figures}

Figure 1. The bio-toilet system and its components.

Figure 2. Schematic representation of the experimental device: laboratory-scale composting reactors.

Figure 3. Molecular weight distribution for dissolved organic matter from the bio-toilet and other sources and treatment processes.

Figure 4. TOC/E260 ratio for five size-fractions of dissolved organic matter from the bio-toilet and other sources and treatment processes.

Figure 5. Dendogram obtained with the Ward method using the squared Euclidian distance.

Figure 6. Evolution of the experimental oxygen utilization rate (OUR).

Figure 7. Evolution of total organic carbon for six size-fractions of dissolved organic matter during the thermophilic biodegradation of faeces.

Figure 8. Transformation and characterization of dissolved organic matter during the thermophilic aerobic biodegradation of faeces.(BTC: the bio-toilet compost)

Figure 9. Evolution of TOC/E260 ratio for five size-fractions of dissolved organic matter during the thermophilic biodegradation of faeces. (BTC: the bio-toilet compost)

Figure 10. KDO/TOC ratio for dissolved organic matter from the bio-toilet and other sources and treatment processes.

Figure 11. Evolution of KDO/TOC ratio during transformation of dissolved organic matter in the bio-toilet system. 


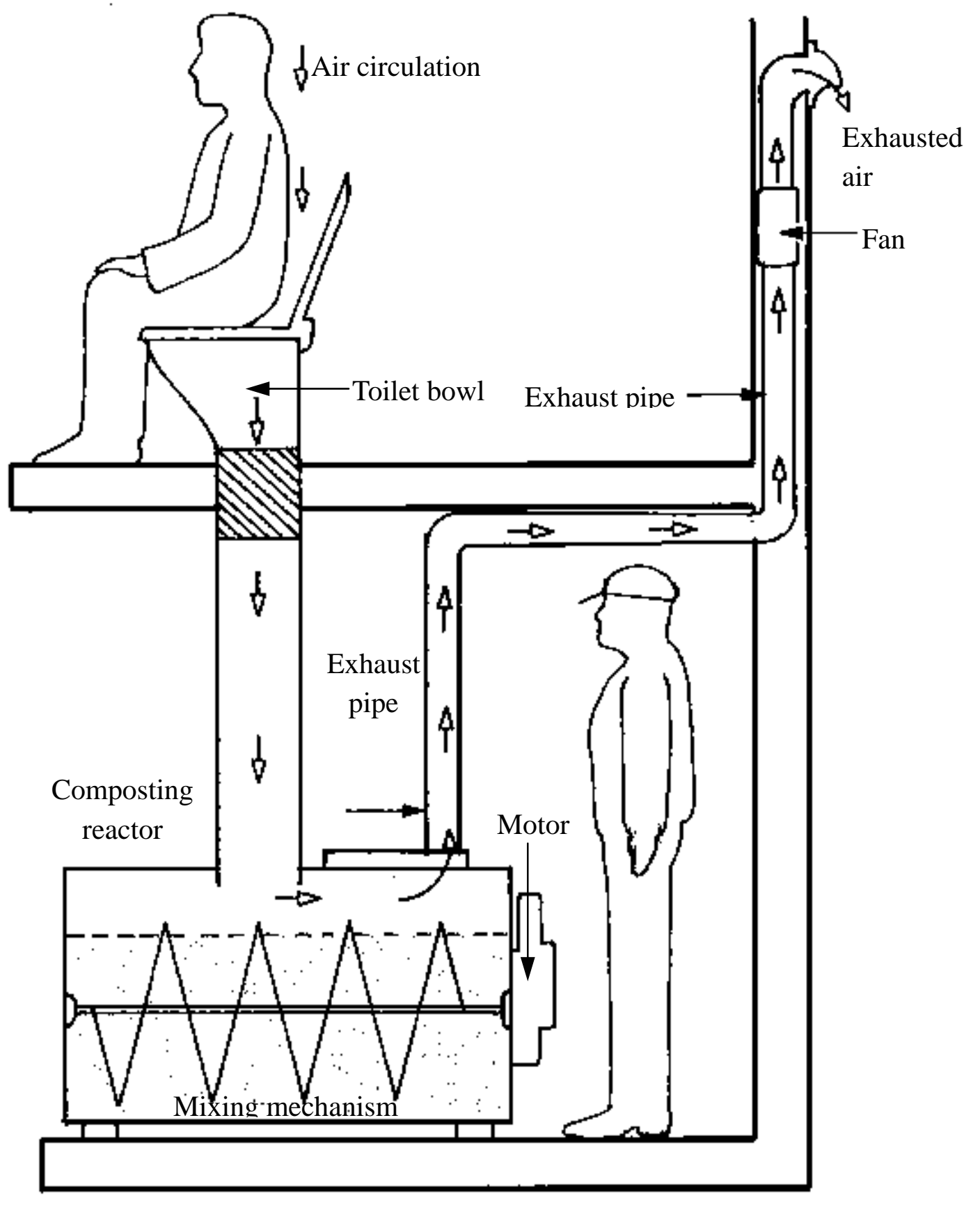

Figure 1. The bio-toilet system and its components. 


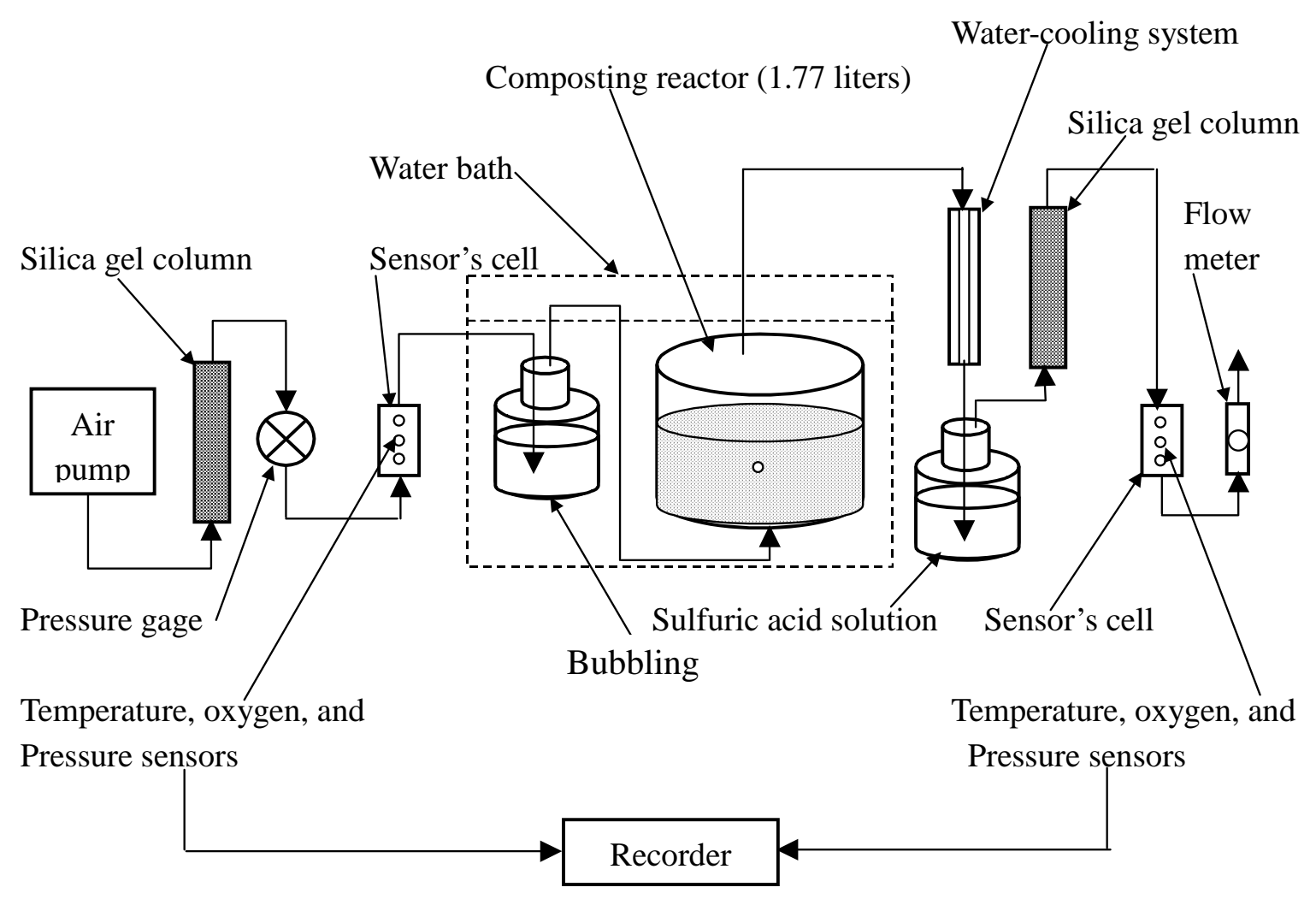

Air circulation

Input pressure: $25 \mathrm{kPa}$ (at the pressure gage)

Figure 2. Schematic representation of the experimental device: laboratory-scale composting reactors (Lopez Zavala et al., 2004). 


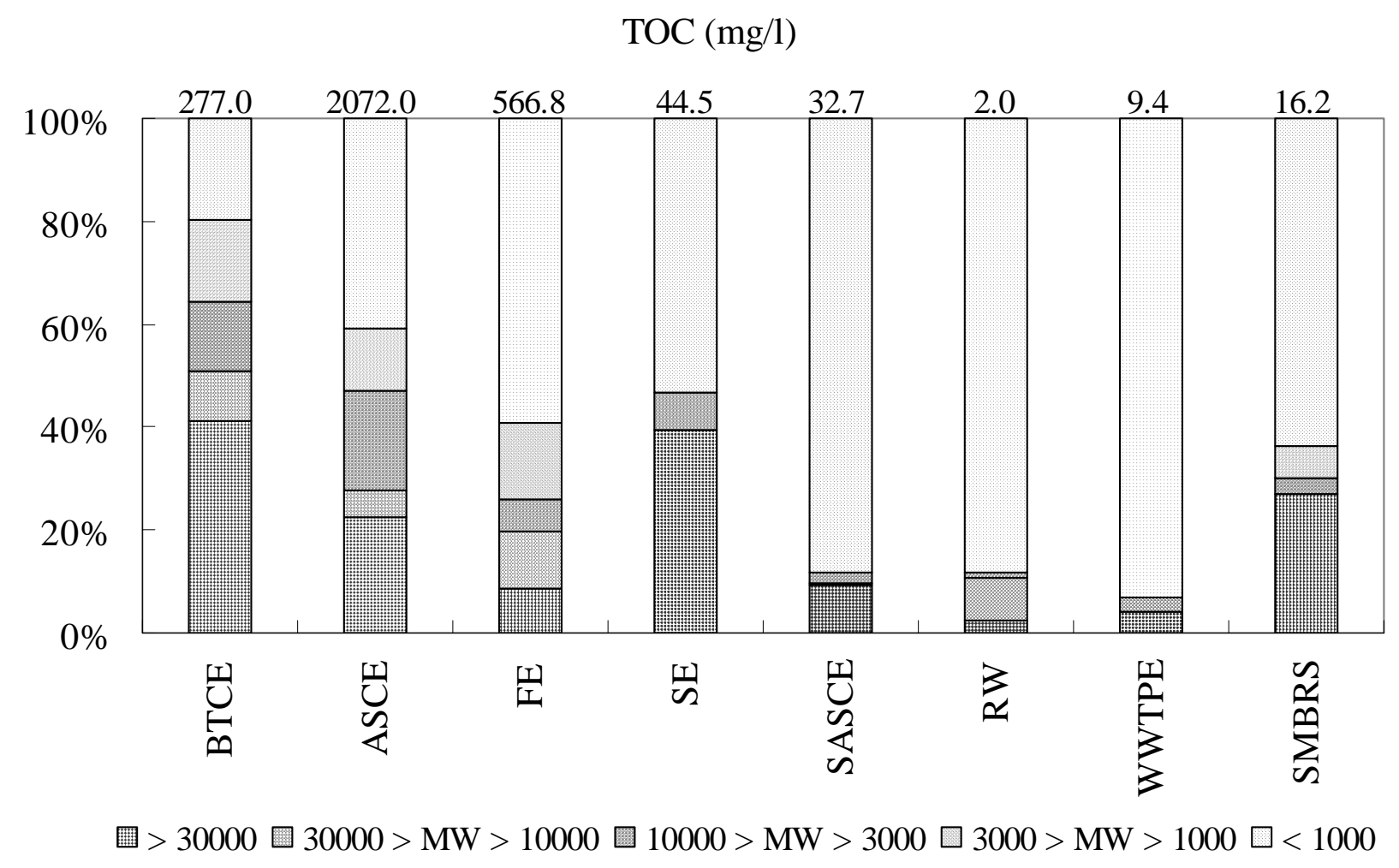

Figure 3. Molecular weight distribution for dissolved organic matter from the bio-toilet and other sources and treatment processes. BTCE: bio-toilet compost extract; ASCE: activated sludge compost extract; FE: faeces extract; SE: soil extract; SASCE: soil with activated sludge compost extract; RW: river water; WWTPE: wastewater treatment plant effluent; SMBRS: submerged membrane bioreactor supernatant. 


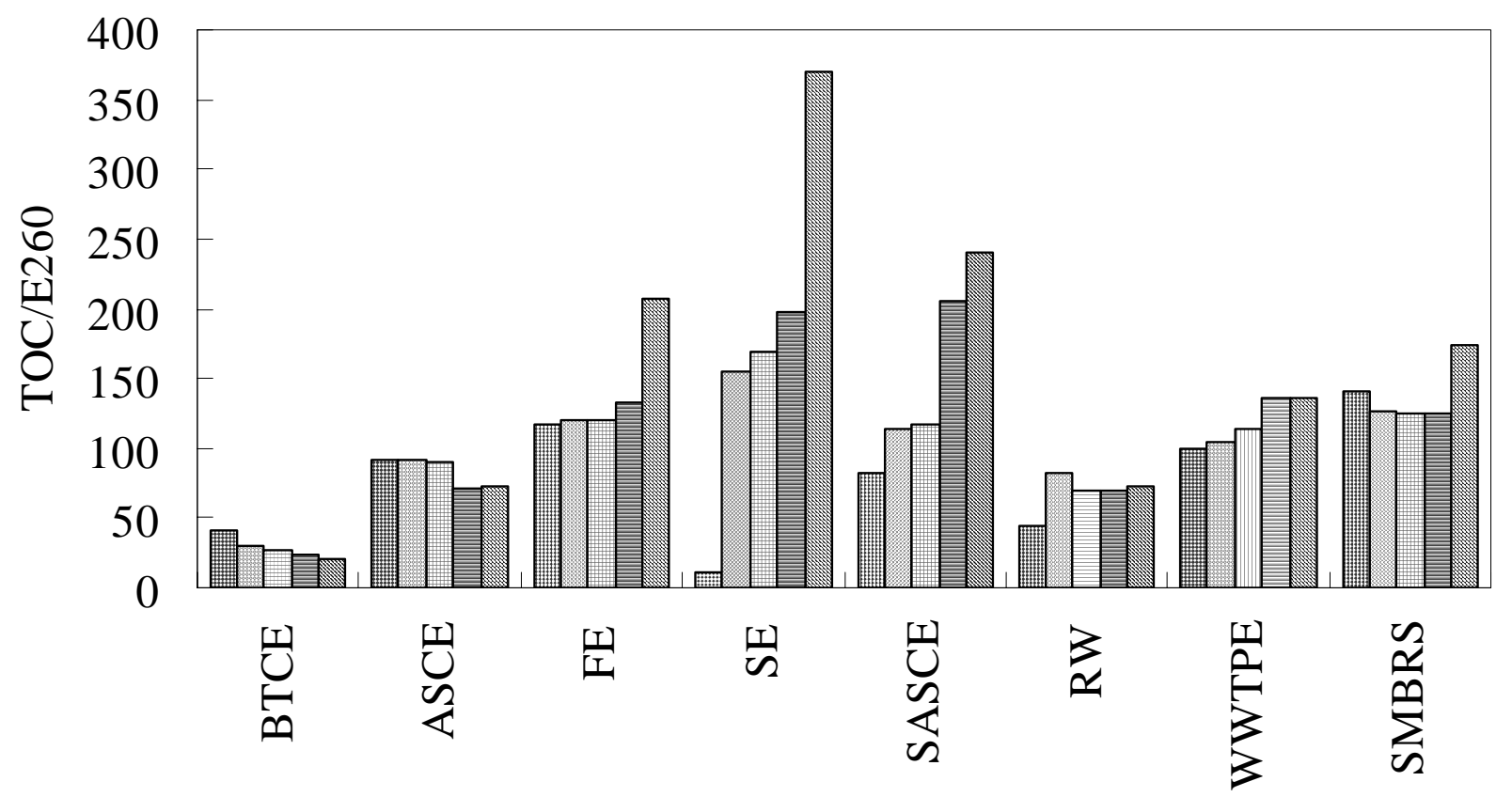

$\square 0.45 \mu \mathrm{m}$ filtrate $\square \mathrm{MW}<30000 \square \mathrm{MW}<10000$ 目 MW $<3000 \square \mathrm{MW}<1000$

Figure 4. TOC/E260 ratio for five size-fractions of dissolved organic matter from the bio-toilet and other sources and treatment processes. 


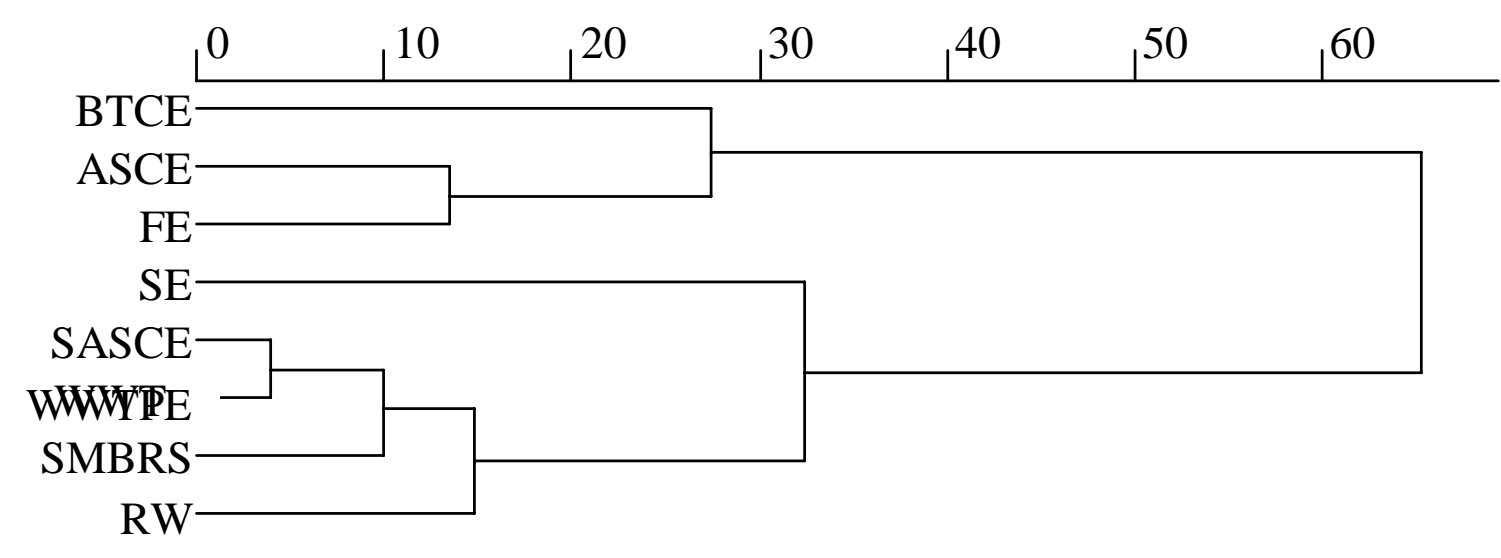

Figure 5. Dendogram obtained with the Ward method using the squared Euclidian distance. 


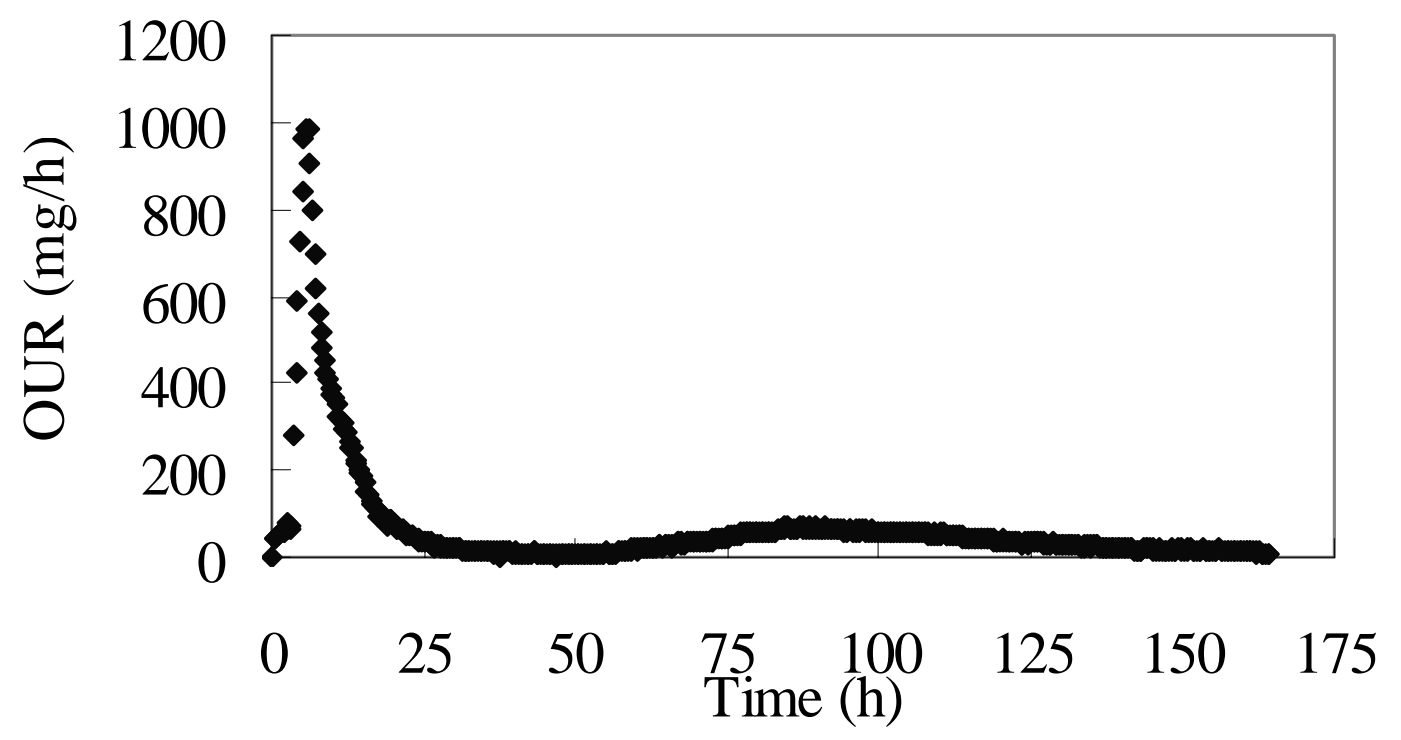

Figure 6. Evolution of the experimental oxygen utilization rate (OUR). 


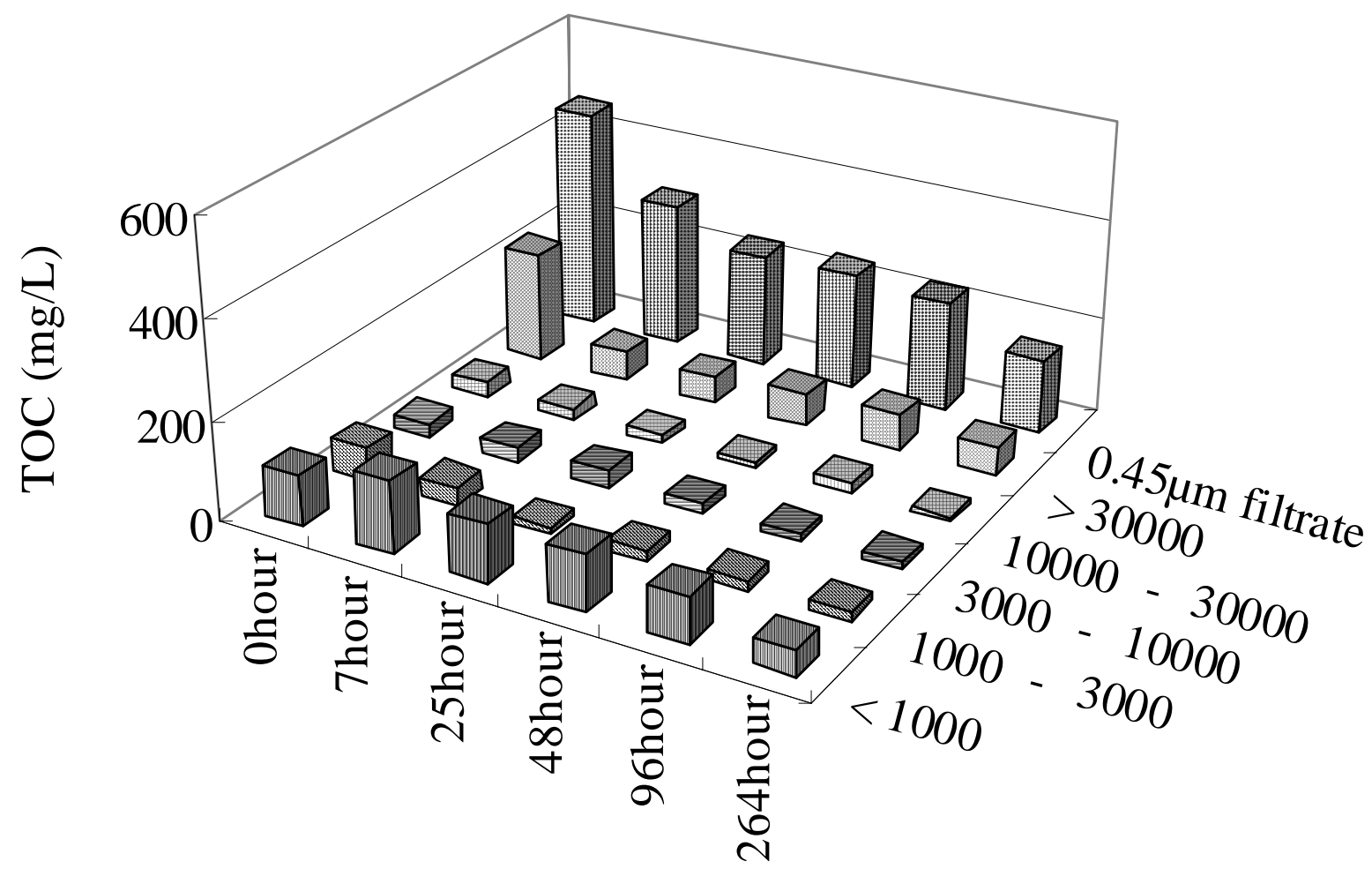

Figure 7. Evolution of total organic carbon for six size-fractions of dissolved organic matter during the thermophilic biodegradation of faeces. 


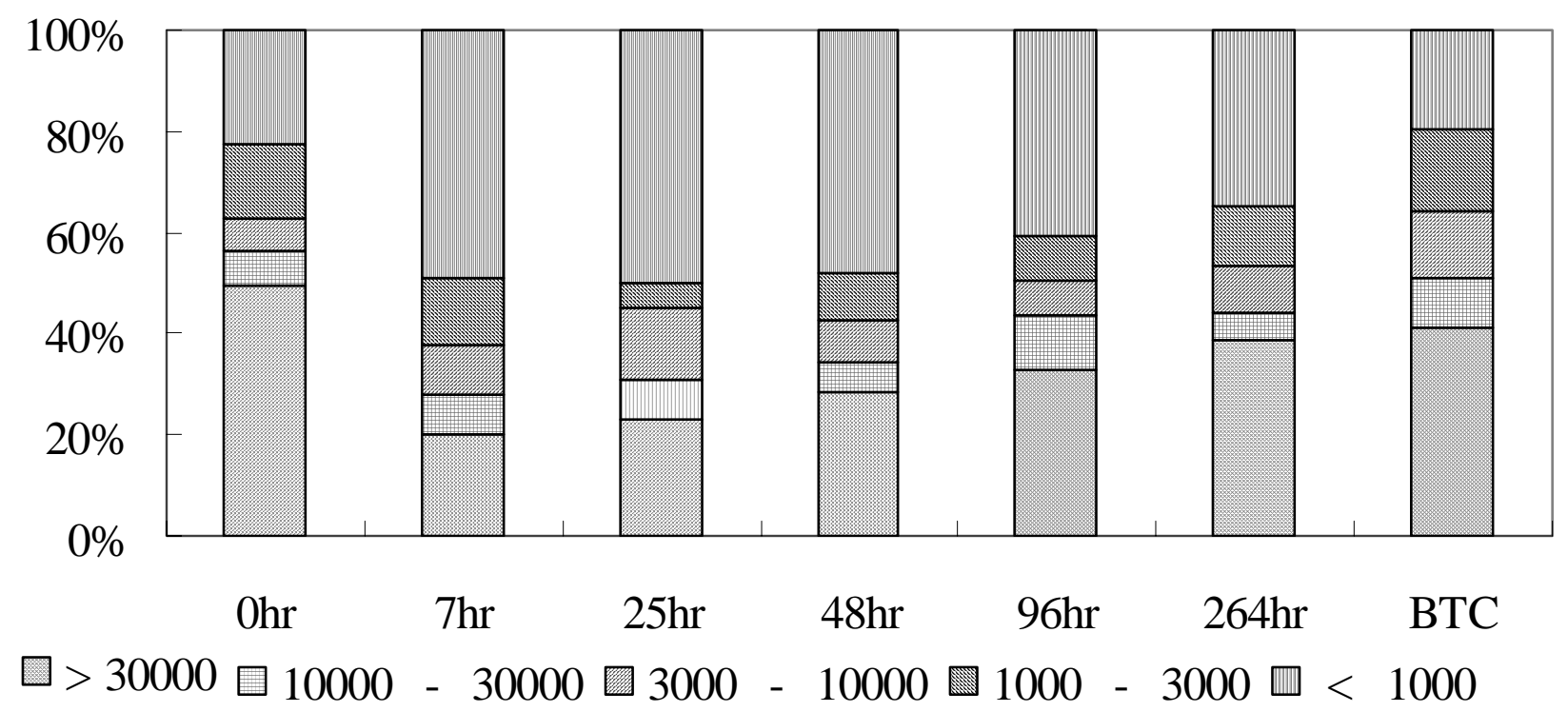

Figure 8. Transformation and characterization of dissolved organic matter during the thermophilic aerobic biodegradation of faeces. (BTC: the bio-toilet compost) 


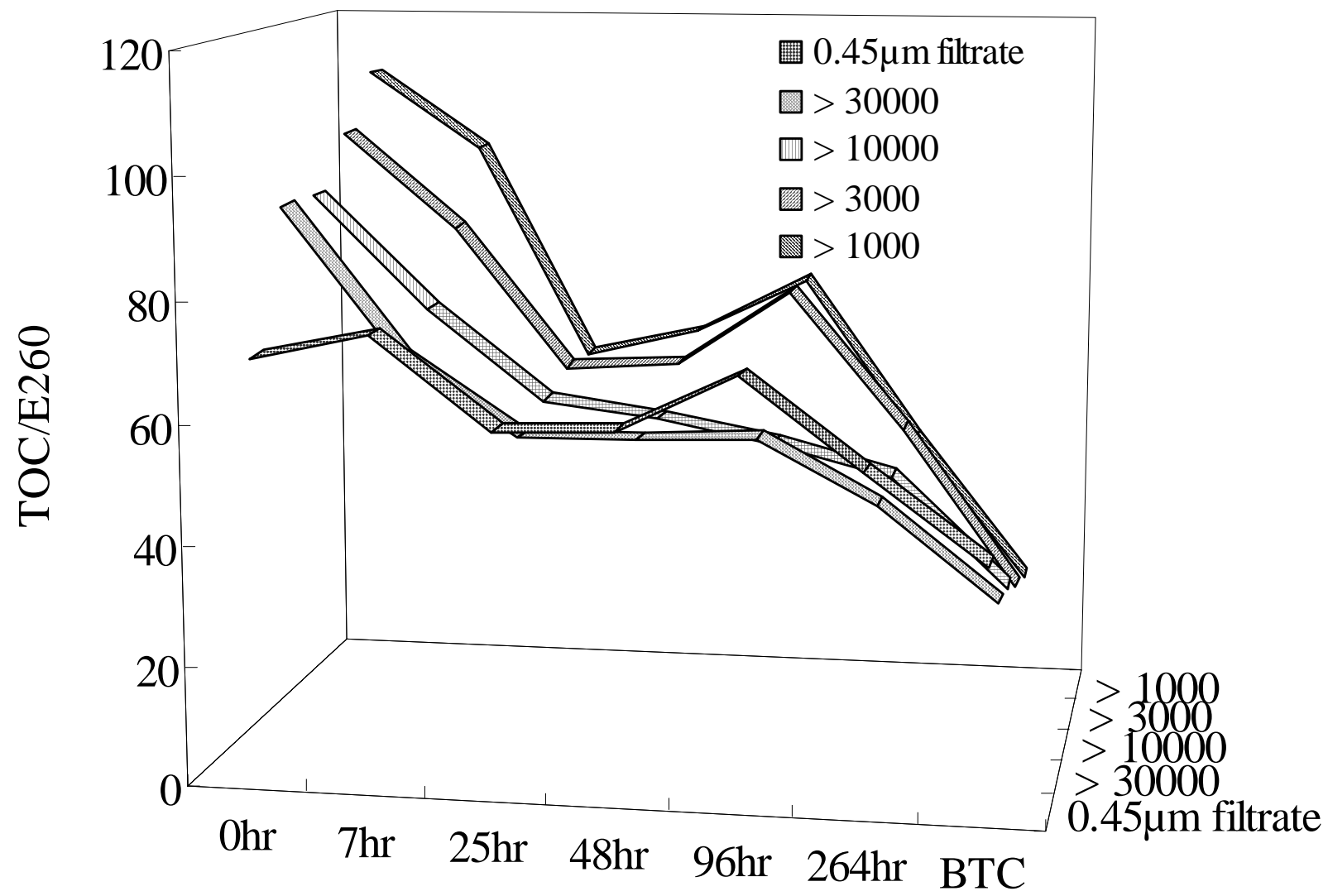

Figure 9. Evolution of TOC/E260 ratio for five size-fractions of dissolved organic matter during the thermophilic biodegradation of faeces. (BTC: the bio-toilet compost) 


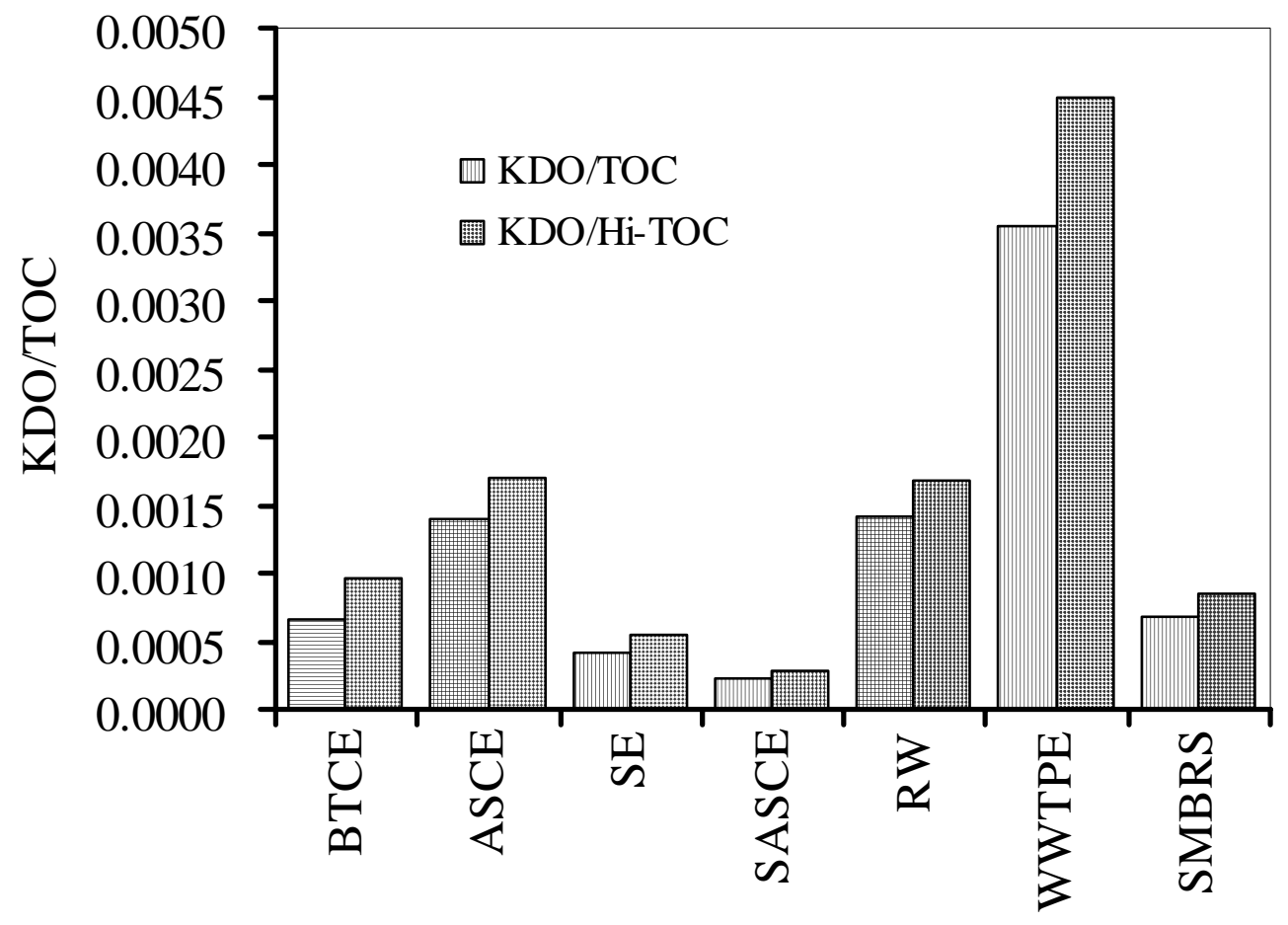

a) Hydrolysed samples

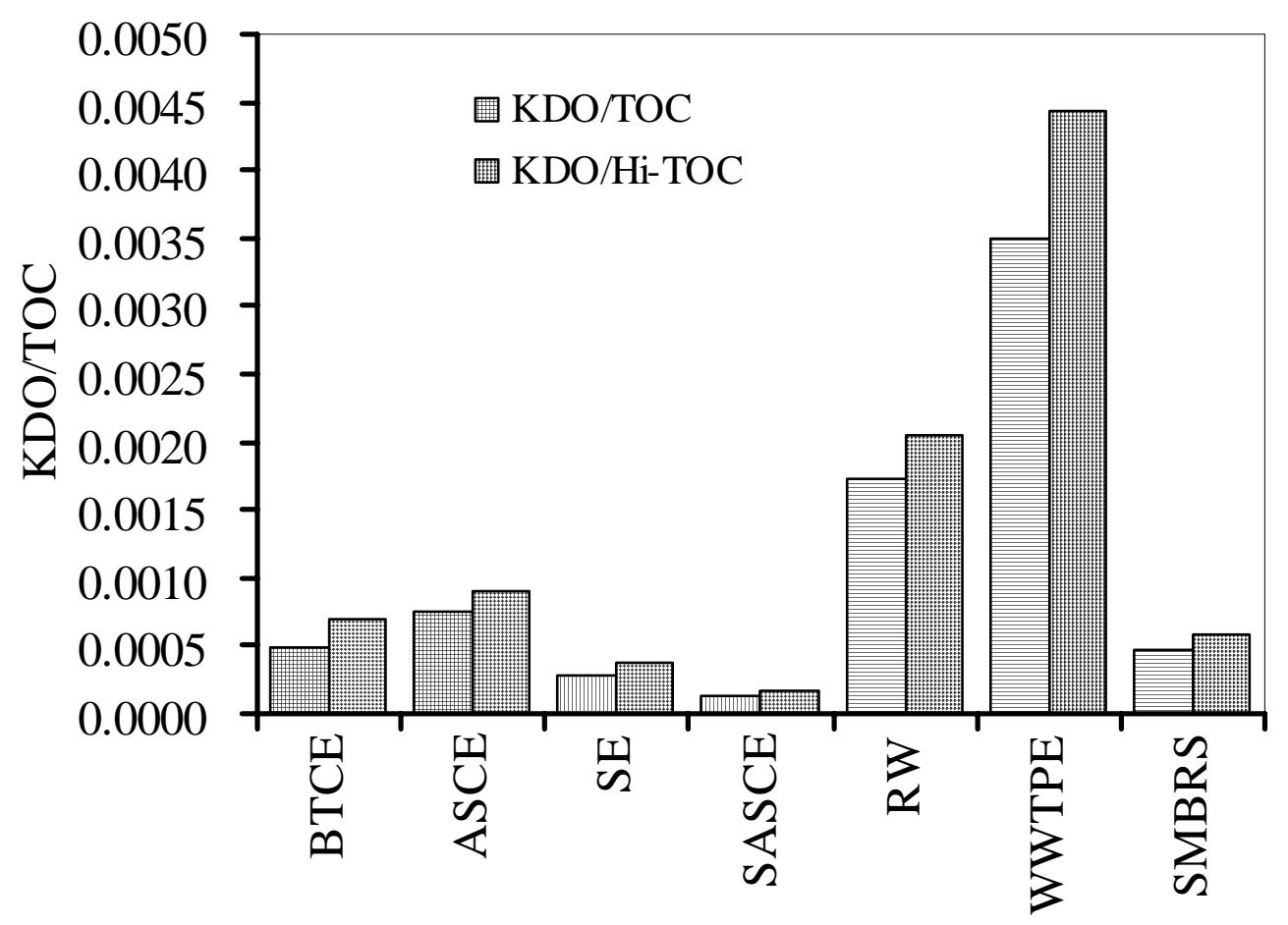

b) Non-hydrolysed samples

Figure 10. KDO/TOC ratio for dissolved organic matter from the bio-toilet and other sources and treatment processes. Hi-TOC is TOC for the hydrophilic fraction. 


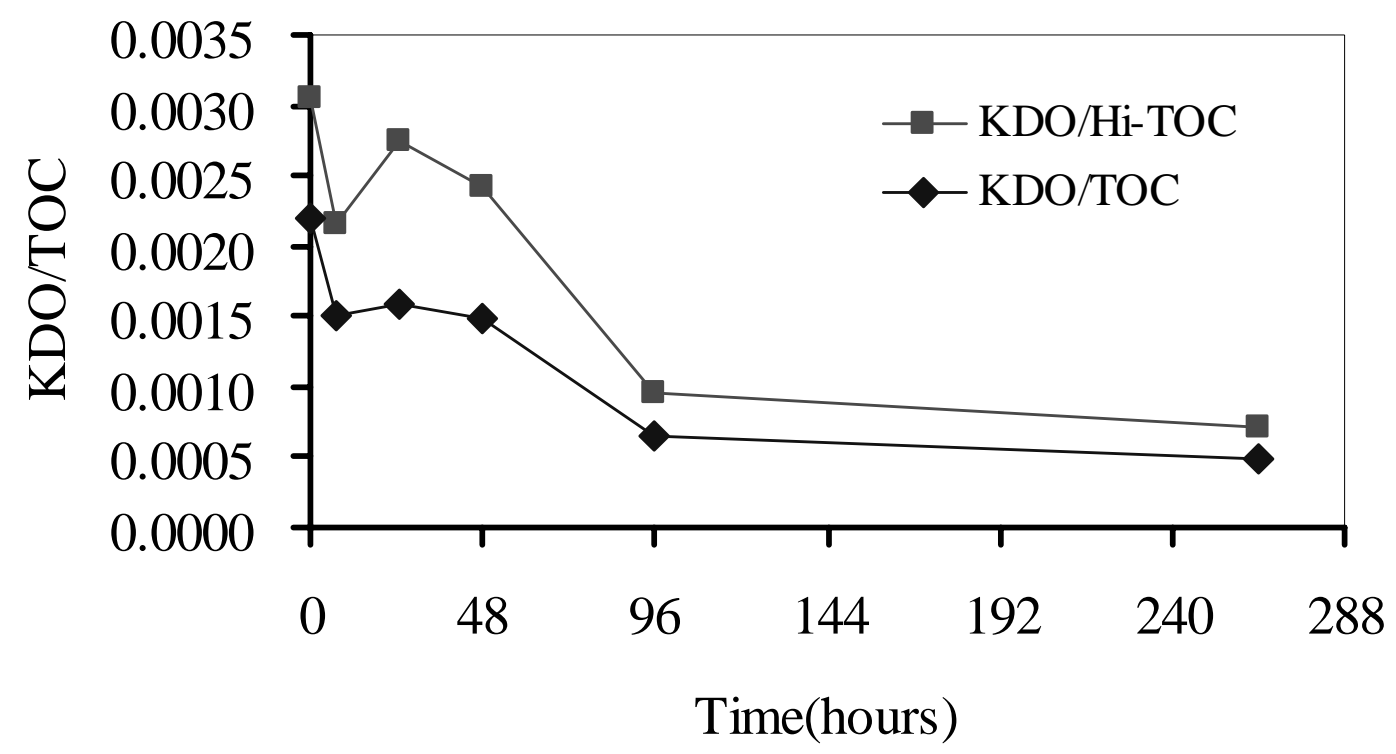

a) Hydrolysed samples

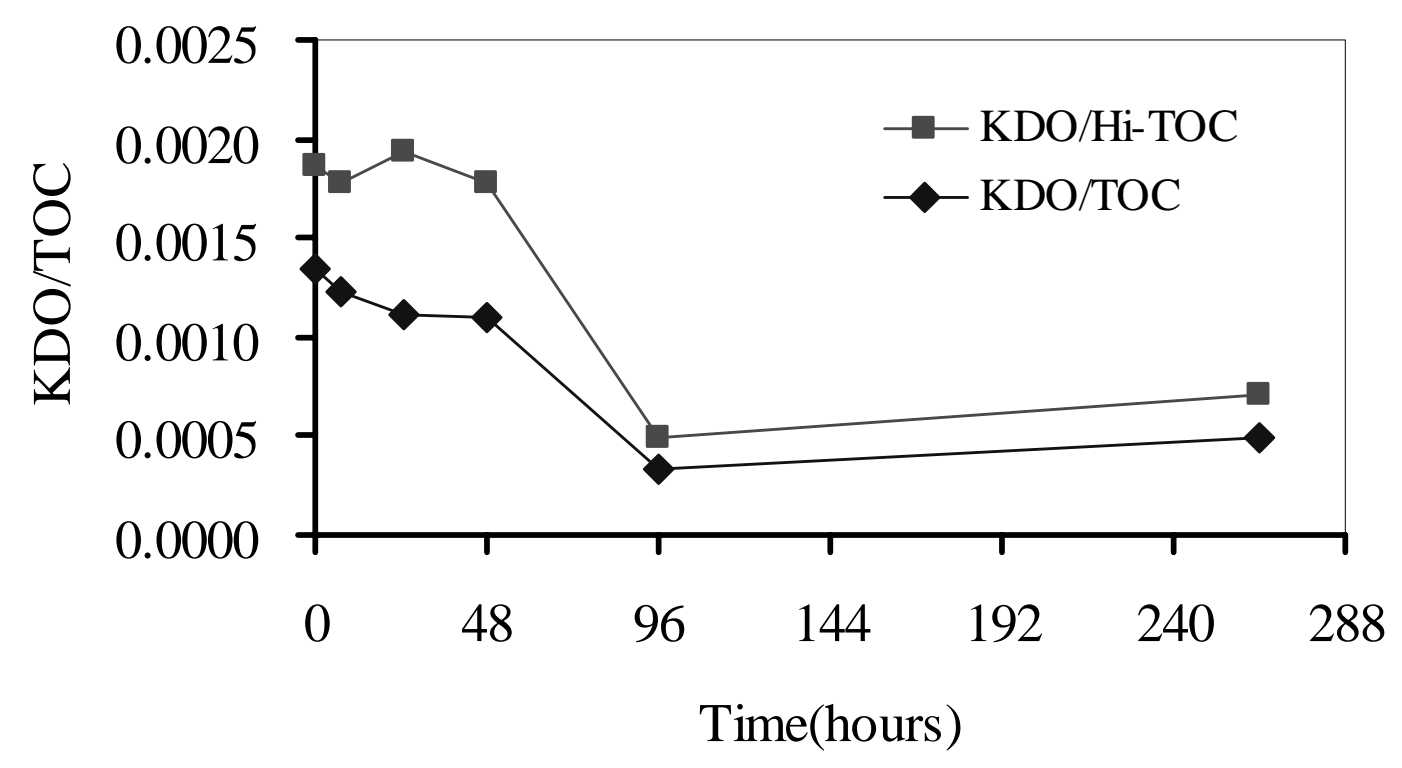

b) Non-hydrolysed samples

Figure 11. Evolution of KDO/TOC ratio during transformation of dissolved organic matter in the bio-toilet system. Hi-TOC is TOC for the hydrophilic fraction. 


\section{List of tables}

Table 1. Samples for characterization of dissolved organic matter

Table 2. Cluster analysis using the Ward method and the squared Euclidean distance. 
Table 1. Samples for characterization of dissolved organic matter

\begin{tabular}{|c|l|}
\hline & \\
\hline BTCE & Compost from bio-toilet \\
\hline ASCE & Compost from activated sludge composting plant in Sapporo \\
\hline FE & Faeces of healthy person \\
\hline SE & Soil from Hokkaido University Experimental Farm \\
\hline SASCE & Soil from farm land where ASCE has been applied for ten years \\
\hline RW & River water ( River A in mountain side in Hokkaido) \\
\hline WWTPE & Effluent from wastewater treatment plant ( Plant B in Sapporo) \\
\hline SMBRS & Effluent from pilot-scale membrane bio-reactor in wastewater treatment Plant C in \\
& Sapporo \\
\hline
\end{tabular}


Table 2. Cluster analysis using the Ward method and the squared Euclidean distance.

\begin{tabular}{ccccc}
\hline Step & Distance & Squared distance & \multicolumn{2}{c}{ Fusion cluster } \\
\hline 1 & 1.73 & 3.01 & 3 & 6 \\
2 & 3.02 & 9.14 & 3 & 7 \\
3 & 3.56 & 12.65 & 4 & 8 \\
4 & 3.70 & 13.72 & 3 & 5 \\
5 & 5.07 & 25.67 & 1 & 4 \\
6 & 5.64 & 31.85 & 2 & 3 \\
7 & 8.00 & 63.97 & 1 & 2 \\
\hline
\end{tabular}

